\title{
Seismic vulnerability assessment of school buildings in Tehran city based on AHP and GIS
}

\author{
M. Panahi ${ }^{1}$, F. Rezaie ${ }^{2}$, and S. A. Meshkani ${ }^{3}$ \\ ${ }^{1}$ Department of Geophysics and Young Researchers and Elites Club, North Tehran Branch, \\ Islamic Azad University, Tehran, Iran \\ ${ }^{2}$ Department of Geophysics, Science and Research Branch, Islamic Azad University, Tehran, Iran \\ ${ }^{3}$ Department of Geology, Tarbiat Moallem University, Tehran, Iran
}

Correspondence to: M. Panahi (panahi2012@yahoo.com)

Received: 5 June 2013 - Published in Nat. Hazards Earth Syst. Sci. Discuss.: 6 September 2013

Revised: 2 February 2014 - Accepted: 27 February 2014 - Published: 24 April 2014

\begin{abstract}
The objective of the current study is to evaluate the seismic vulnerability of school buildings in Tehran city based on the analytic hierarchy process (AHP) and geographical information system (GIS). To this end, the peak ground acceleration, slope, and soil liquefaction layers were utilized for developing a geotechnical map. Also, the construction materials of structures, age of construction, the quality, and the seismic resonance coefficient layers were defined as major factors affecting the structural vulnerability of school buildings. Then, the AHP method was applied to assess the priority rank and weight of criteria (layers) and alternatives (classes) of each criterion via pairwise comparison in all levels. Finally, the geotechnical and structural spatial layers were overlaid to develop the seismic vulnerability map of school buildings in Tehran. The results indicated that only in 72 (about $3 \%$ ) out of 2125 school buildings of the study area will the destruction rate be very high and therefore their reconstruction should seriously be considered.
\end{abstract}

\section{Introduction}

The Iranian plateau is located between the continental convergence of the Arabian and Eurasian plates in the central part of the Alpine-Himalayan seismic belt. Thus, the seismicity of this area is very high and the frequent occurrence of moderate to large earthquakes such as Buin Zahra (1962), Tabas (1978), Manjil-Rudbar (1990), Avaj (2002), Bam (2003), Zarand (2005) and Varzaqan (2012) have caused heavy casualties and considerable financial losses to the country.
Tehran, the capital of Iran, with a population of about 12 million, is one of the most densely populated metropolises of the world. This megalopolis is located in an extremely seismic zone at the foothills of the southern Elburz Mountains and surrounded by several active and major faults such as the Mosha, North Tehran and North and South Rey faults. Movement of any of them could lead to a considerable loss of human life and to substantial financial damage. There are also some minor faults like Abasabad, Niavaran and Kowsar, some of which might cause surface rupture and thus increase the amount of damage during an earthquake. Therefore, for the above-mentioned reasons, developing a seismic vulnerability map based on the movements of active and major faults seems critical and worthwhile.

Nowadays, vulnerability assessment and modelling behaviour of buildings with regard to earthquakes have turned into a major concept in hazards studies (e.g. Rashed and Weeks, 2003; Maithani and Sokhi, 2004; Servi, 2004; Gulati, 2006; Thapaliya, 2006; Cole et al., 2008; Nath and Thingbaijam, 2009). Therefore, many Iranian researchers such as Zahraie and Ershad (2005), Aghataher et al. (2008), Amini Hosseini et al. (2009), Hataminejad et al. (2009) and Hashemi and Alesheikh (2012) have identified the effective factors in earthquake hazard assessment and applied various methods in developing a seismic hazard map. Among these studies, identification and reduction of the seismic vulnerability of school buildings against earthquakes is essential since, according to the Standard 2800 (BHRC: Building and Housing Research Center, 2005), school buildings are among the most vital structures, with their upgrading against earthquake being highly important for the reduction in loss of life 
as well as properties. Based on the mentioned reasons, in the current study, the main factors in the seismic vulnerability of school buildings in Tehran are identified, and structural information and geological and geotechnical data have been collected. The weight assigned to the criteria (layers) and the alternatives (classes) of each criterion are calculated based on analytic hierarchy process (AHP) and the geotechnical and structural vulnerability maps have been developed using geographical information system (GIS). Finally, the seismic status of school buildings at the time of earthquake occurrence has been analysed by overlaying these two maps.

\section{Study area}

The rapid growth of urbanization in seismic regions like Tehran has given rise to the likelihood of these cities being vulnerable to destructive earthquakes due to buildings having been constructed without considering engineering principles and disregarding the geological and geotechnical characteristics of the region. Tehran, which lies in an area of about $615 \mathrm{~km}^{2}$, is located between the latitudes $51^{\circ} 15^{\prime}$ and $51^{\circ} 35^{\prime} \mathrm{E}$ and the longitudes $35^{\circ} 33^{\prime}$ and $35^{\circ} 50^{\prime} \mathrm{N}$, and is limited by the Elburz Mountains in the north and by Bibi Shahrbanoo and Sepayeh heights in the east. To date, the city has experienced strong earthquakes greater than $M_{\mathrm{s}}=6.5$ (Ashtari Jafari, 2010), with most of them occurring as a result of the movement on the North Tehran, Mosha, North and South Rey, Garmsar and Eshtehard faults (Fig. 1).

The South and North Rey faults are about $20 \mathrm{~km}$ long with a WNW-ESE strike and reverse mechanism distributed throughout both sides of the Rey depression in the southern part of Tehran plain (Berberian et al., 1985). The distance between these two faults ranges from 3 to $5 \mathrm{~km}$, and it seems that they are branches of one original fault and have a similar origin. Available information shows that there is no record of activity for these faults over the last $1000 \mathrm{yr}$, and the most recent earthquake due to these faults occurred in $855 \mathrm{BC}$ with a magnitude of $M_{\mathrm{w}}=7$ (JICA: Japan International Cooperation Agency and CEST: Center for Earthquake and Environmental Studies of Tehran, 2000). Therefore, the South and North Rey faults are the most prominent faults in the southern part of Tehran and they can cause strong earthquakes in the future.

In addition, according to the statistics developed by Iran's Ministry of Education, there are 2125 schools with a total of 1291628 students and teachers in Tehran. Thus, heavily attended schools and their distribution in a big city such as Tehran with high seismic activity and structures vulnerable in earthquakes necessitate a vulnerability assessment of the structures and seismic retrofitting for school buildings.
Table 1. Fundamental scale for pairwise comparisons (Saaty, 2004).

\begin{tabular}{ll}
\hline Weight/rank & Intensities \\
\hline 1 & equal \\
3 & moderately dominant \\
5 & strongly dominant \\
7 & very strongly dominant \\
9 & extremely dominant \\
$2,4,6,8$ & intermediate values \\
Reciprocals & for inverse judgements \\
\hline
\end{tabular}

\section{Methodology}

Usually, in order to make a decision, the decision makers should consider certain criteria. If these criteria are quantitative, there are slightly different mathematical methods for addressing them but, since in much decision making the respective criteria are both quantitative and qualitative and are sometimes in conflict with each other, addressing them needs specific methods such as multi-criteria decision making (MCDM) techniques. MCDM includes a series of techniques (such as sum of weights or correlation analysis) that allows the experts and respective groups to assess, assign scores to and rank a range of criteria related to a particular issue (Malczewski, 2004; Dodgson et al., 2009). Thus, by a combination of MCDM and methods based on GIS, which has a unique capacity for the management and analysis of spatial data, a wide range of spatial decisions can be obtained.

AHP is one of the most common and applied techniques of MCDM, presented by Saaty (1980). The method is based on the three principles of decomposition, comparative judgment and synthesizing of priorities. In the decomposition stage, we need to disintegrate the decision making problems into various elements in hierarchy form. Regarding this, the first stage is to create a tree structure for criteria and sub-criteria. The principle of comparative judgement involves a pairwise comparison of available alternatives in a hierarchical level; the elements of a level are compared with other elements of the same level and their relative importance is calculated as shown in Table 1.

These weights can be calculated individually or by a group of experts. Thus, verification of pairwise comparisons to assess the accuracy of comparisons between two options is necessary through verifying the consistency of comparisons. To this end, the consistency index (CI) is used as follows:

$\mathrm{CI}=\frac{\lambda \max -n}{n-1}$,

where $\mathrm{CI}$ is the consistency index; $\lambda_{\max }$ is the largest or principal eigenvalue of the pairwise comparison matrix, and $n$ is the order of the matrix. When the matrix has a complete compatibility, $\mathrm{CI}=0$. The bigger $\mathrm{CI}$ is, the worse the consistency of the matrix. Then, the consistency ratio (CR) is calculated 


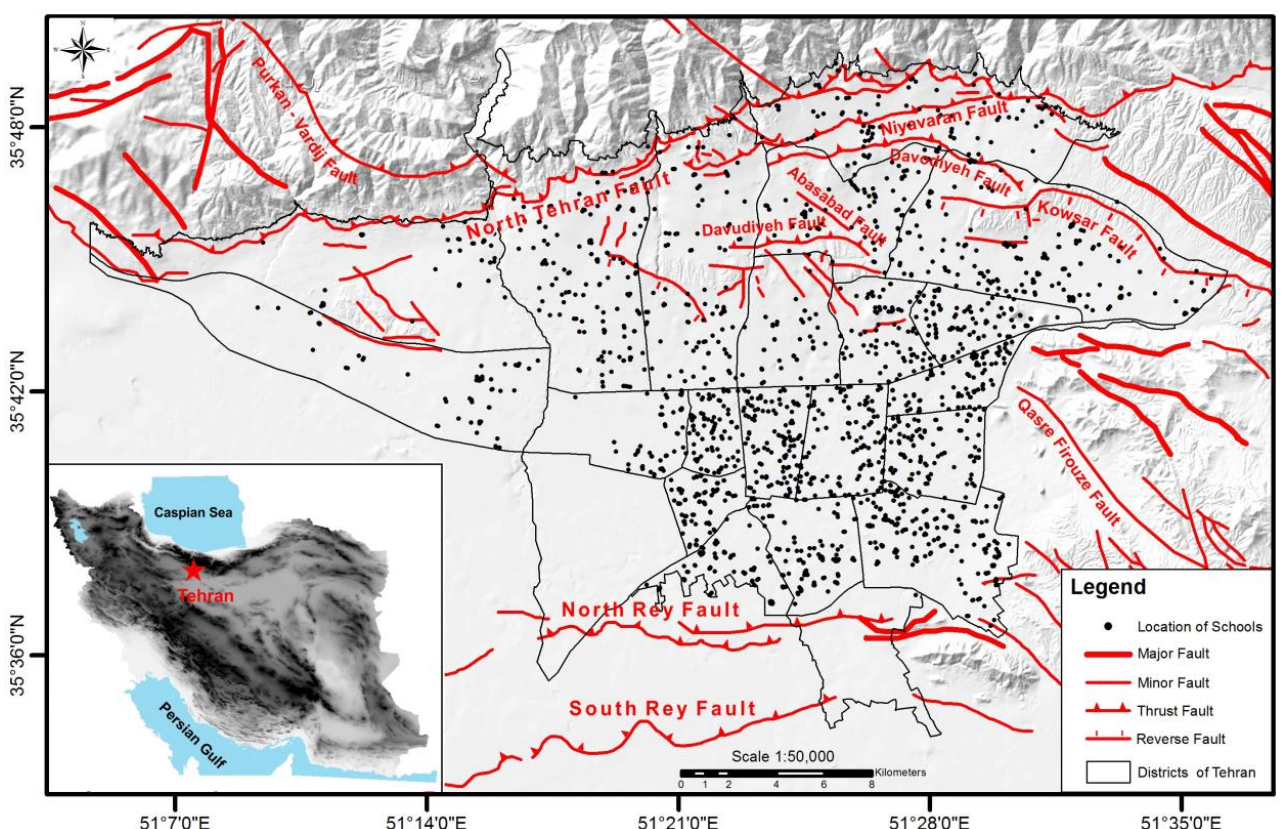

Fig. 1. Study area and the location of Tehran school buildings.

as

$\mathrm{CR}=\frac{\mathrm{CI}}{\mathrm{RI}}$,

where RI is the average of the resulting consistency index depending on the order of the matrix (Saaty, 1977). When $\mathrm{CR}$ is less than 0.10 , the matrix has a reasonable consistency. When it is not, the matrix should be changed and the original values in the pairwise comparison matrix must be revised by the decision maker. The calculated results of weight can be accepted once the consistency ratio is satisfactory.

In this research, analytic hierarchy process has been used to combine and analyse spatial information to develop a seismic vulnerability map for school buildings in Tehran. With regard to this, the steps taken throughout the study are described as follows and the flowchart for the preparation of the seismic vulnerability map of the study area based on AHP and GIS is shown in Fig. 2.

The major steps are summarized as follows:

1. definition of the objective (seismic vulnerability assessment of school buildings).

2. identifying the main factors and influencing indicators in the development of a seismic vulnerability map.

3. collecting, preparing and transferring the data to the GIS environment, and classifying and ranking them.

4. applying the analytic hierarchy process and assigning weights to the factors and indicators via calculation of the pairwise comparison matrix.
5. calculating $\mathrm{CR}$ and repeating weighing of factors if $\mathrm{CR}$ is greater than 0.1 and estimating of overall weights and assigning them to each layer.

6. developing the geotechnical and structural vulnerability map separately by overlaying the weighted raster layers. The formula proposed by Malczewski (1999) for obtaining the total scores was applied in this study. Accordingly, the weight of each pixel of the output in the vulnerability maps $\left(W_{i}\right)$ was calculated by using the following summation:

$W_{i}=\sum_{j} x_{i j} w_{j}$

where $x_{i j}$ is the rank value of the $i$ th class with respect to the $j$ th layer, and $w_{j}$ is the normalized weight of the $j$ th layer. The final weight can be obtained through multiplying the normalized weight value of each layer in the standardized rank value given to the classes of that layer and the sum of them.

7. finally, since in determining the vulnerability of school buildings against earthquake all geotechnical and structural factors should be considered simultaneously, the seismic vulnerability of school buildings in Tehran municipality was calculated by overlaying the two maps obtained. 

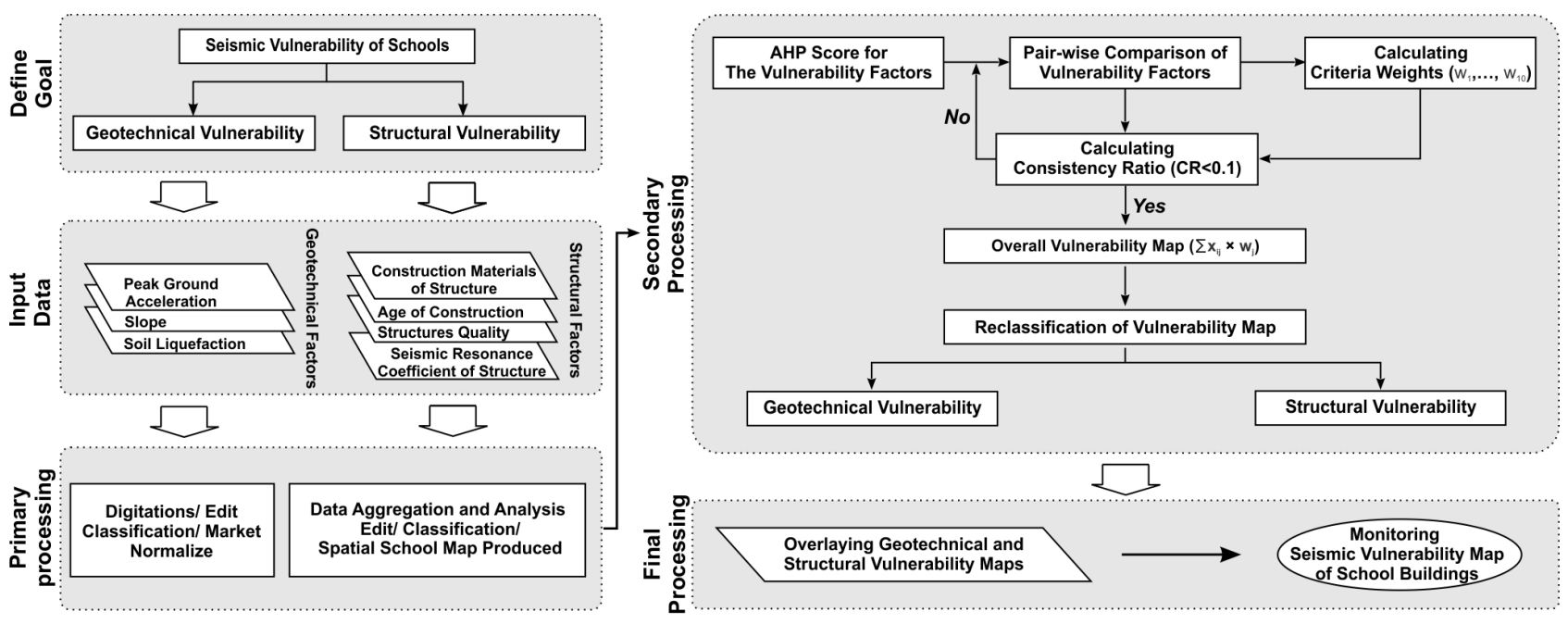

Fig. 2. A flowchart illustrating the methodology used in various stages of the research for the preparation of the seismic vulnerability map of the study area.

\section{Data preparation and analysis}

\subsection{Geotechnical vulnerability factors}

In seismic areas, the assessment of geotechnical seismic vulnerability is essential for urban expansion and development; therefore, neglecting it and not identifying areas with a high potential of earthquake occurrences increases the likelihood of seismic vulnerability and damage. Generally, seismic hazards can be estimated by analysing past earthquake activity in the region, evidence regarding the stress-bearing qualities of structures within fault areas, and how seismic waves travel through the crust and overlying soil beneath the sites. It is worth noting that, at the time of an earthquake, the incidence of surface rupture, landslides and soil liquefaction in addition to peak ground acceleration (PGA), are the secondary events brought about as a result of ground movement and can intensify the seismic vulnerability and damage. Therefore, they must be considered when estimating the overall seismic vulnerability. But the occurrence of these events is related to the subsurface plane above a major movement release or to the secondary effects of folding, e.g. lateral spreading. Unfortunately, as we did not have sufficient data on subsurface layers in Tehran and did not have the chance to study surface rupture, landslides and soil liquefaction, the results of other researchers' studies are used.

\subsubsection{Peak ground acceleration}

Major characteristics of a strong ground motion such as duration, amplitude and frequency content have significant effects on the distribution of damage and deformations occurring in the surface of the Earth during strong earthquakes. Generally, PGA that correlates with the amount of the activity of nearby faults in the region is the most important issue in the context of seismic vulnerability. In the current study, according to the map of PGA presented by JICA and CEST (2000) for the Rey fault scenario, the PGA is about $200 \mathrm{Gal}$ in the north and over $400 \mathrm{Gal}$ in the southern parts of Tehran in the case of the activity of the Rey fault. Thus, the great the PGA is, the higher is the seismic vulnerability of an area (Fig. 3a).

\subsubsection{Slope}

The mountainous topography of Iran in most areas, high tectonic and seismic activity as well as various geological and climatic conditions of the country provide a wide range of natural conditions for the occurrence of landslides. The foothills of Tehran provide appropriate conditions for landslide incidence due to the proximity to active fault systems and relatively high slopes. But in recent decades, population growth and the rise of construction in foothills and mountainside regions of northern and eastern parts of Tehran have led to a significant increase in the risks and losses because of the occurrence of landslides in these areas (Safari and Moghimi, 2010). For above-mentioned reasons, identifying vulnerable areas and the regions with a high potential for landslides is critically important (Fig. 3b).

\subsubsection{Soil liquefaction}

The phenomenon of soil liquefaction in the sandy soil below structures is one of the most important causes of collapse at the time of earthquake occurrence. Since most of the soil of Tehran, especially in the southeastern part, is alluvial and sandy, and since the water-saturated and loose state of soil in this region is the result of the lack of drainage channels and a high level of underground water (Askari and Kasaie, 2003), soil forms a pulp during earthquakes. So even buildings not damaged by horizontal earthquake force will tilt or become 


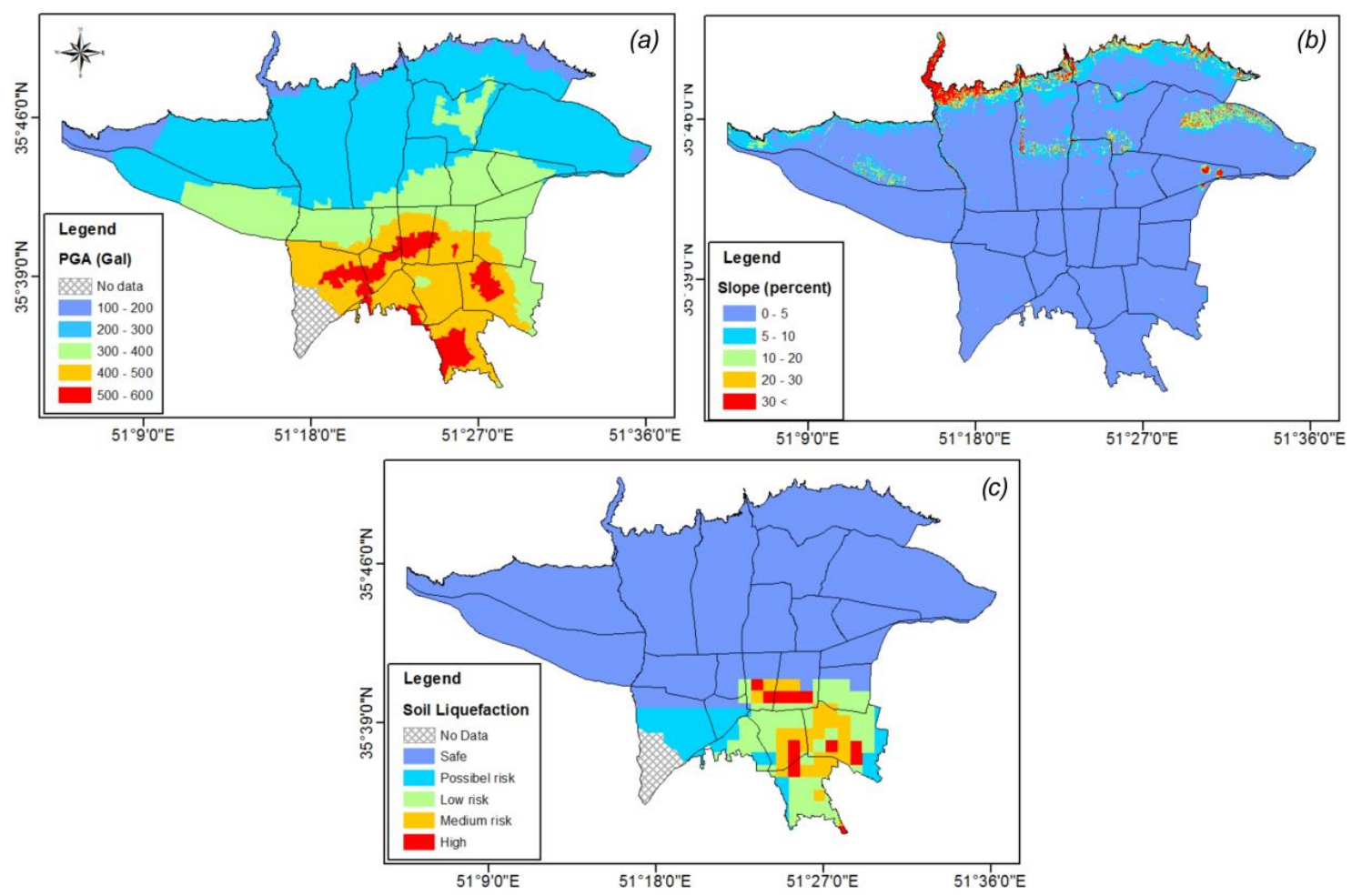

Fig. 3. (a) Distribution of PGA for the Rey fault scenario, (b) slope, (c) soil liquefaction in Tehran metropolis.
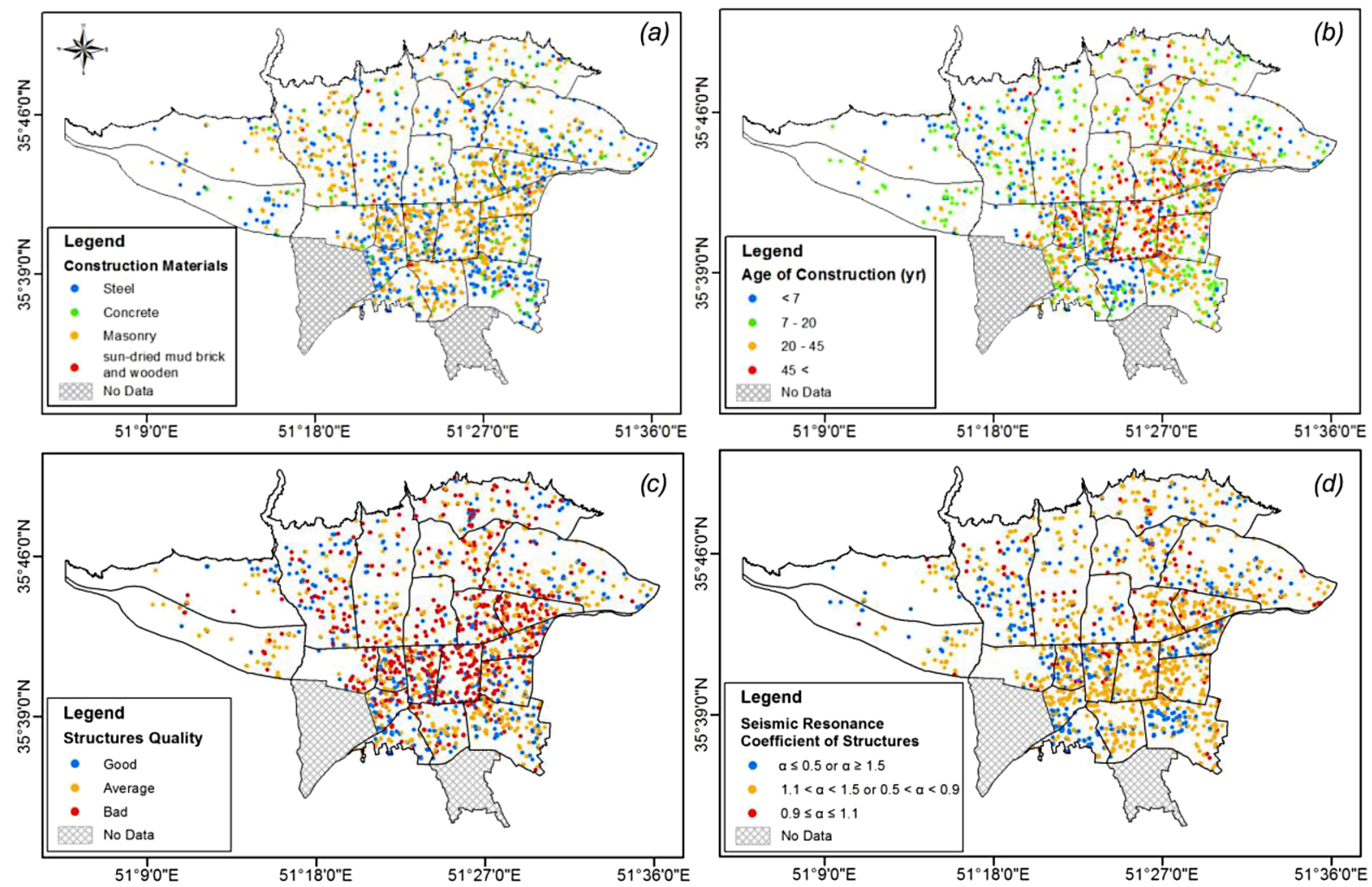

Fig. 4. School distribution by (a) construction materials of structures, (b) age of construction, (c) structure quality, and (d) seismic resonance coefficient of school buildings in Tehran metropolis. 
completely inverted. Because of liquefaction, the amount of damage depends on PGA, shaking duration, soil porosity and amplitude of the applied shear stress on the soil mass during an earthquake (Seed and Idriss, 1971). Therefore, because of soil liquefaction, the structures in the southeast of Tehran are very vulnerable during strong ground motions. In contrast, in northern areas, due to soil type and fabric, and in the southwestern part, due to the low level of underground water, the probability of liquefaction occurrence is very low (Fig. 3c).

\subsection{Structural vulnerability factors}

The antiquity and large size of Tehran as well as the variety of its citizens' livelihoods mean that the structures of this metropolis are very diverse. In general, structures of Tehran include Qajar era structures which are around $100 \mathrm{yr}$ old, villages merged with Tehran with buildings dating back to 20 to $50 \mathrm{yr}$ ago, and new structures and towers. Therefore, in order to prepare the structural vulnerability of a city with such a distribution and variation of native structures, we need to use the experiences of past earthquakes, the Standard 2800 (BHRC, 2005), and the articles written on this topic (Arya, 1967; JICA and CEST, 2000; Zangiabadi and Tabrizi, 2000; Zahraie and Ershad, 2005; Thapaliya, 2006; Aghataher et al., 2008; Sharifzadegan and Fathi, 2008; Hataminejad et al., 2009; Zekai, 2011). To this end, after extracting important factors such as construction materials, age of construction, quality, and seismic resonance as well as the coefficient of structures, and weighting them, the structural vulnerability map was developed.

It is worth noting that in this part of the study more categorizations have been done on the basis of Standard 2800, which is a set of regulations developed by the Iranian Building and Housing Research Center based on the experiences of past earthquakes. It is the only scientific and official reference to determine how to design seismic-resistant structures and how to assess seismic vulnerability of available buildings during earthquakes. According to this regulation, the major seismic stability of structures is dependent on the construction materials, age of construction, quality, and seismic resonance coefficient of buildings. Also, in Standard 2800 each of these factors is divided into subfactors based on PGA of earthquakes.

\subsubsection{Construction materials of structures}

There are different classifications for the materials used in the construction of buildings. One of the most important is the ranking done in Standard 2800 (BHRC, 2005) for earthquake-proof structures. In this regulation, structures are divided into four categories according to the materials used for construction; these are steel, concrete or masonry buildings (brick and cement block or stone) as well as sun-dried mud brick and wooden buildings. The results of the research by experts in laboratory experiments and observations from previous earthquakes indicate that sun-dried mud brick buildings are the most vulnerable structures which totally collapse during an earthquake with a magnitude greater than 6 (Mahdizadeh, 2011); the vulnerability of masonry, concrete and steel buildings decreases (Tavakoli and Tavakoli, 1993; JICA and CEST, 2000; Ghayamghamian and Khanzade, 2008; Ghayamghamian et al., 2012) (Fig. 4a).

\subsubsection{Age of construction}

The optimal lifetime of structures in Iran is usually $30 \mathrm{yr}$. The longer a building's lifetime is, the greater is its vulnerability. Furthermore, according to Standard 2800 (BHRC, 2005), the amount of structural damage shows a step-linear function in an earthquake because the quality and the type of construction materials changed at each period during various editions of the regulations (BHRC, 1988, 1999, 2005). Thus the structures can be divided into four groups according to their vulnerability: younger than $7 \mathrm{yr}$, between 7-20, 20-45, and older than $45 \mathrm{yr}$ (JICA and CEST, 2000) (Fig. 4b). However, older buildings do not enjoy adequate safety and are likely to be vulnerable to severe damage or total collapse under strong seismic excitations.

\subsubsection{Structure quality}

Building a structure involves the interaction of different groups, and each of them has the responsibility for different parts of that building. Therefore, the quality of a structure depends on various factors, such as the level of the employer's education and income, the standards of structural design, the quality of materials used in the manufacture, and the insurance status of the structure (Sharifzadegan and Fathi, 2008; Hataminejad et al., 2009). Taking all of the above-mentioned parameters into consideration and after having studied the characteristics of structures and sometimes having done necessary tests, the Iranian experts of the Schools Renovation and Mobilization Organization have divided school buildings into three classes according to the quality of construction, namely good, average and bad structures (Fig. 4c).

\subsubsection{Seismic resonance coefficient of structures}

Each structure shows different seismic responses during an earthquake, depending on the specifications of the structure and its height above ground. Therefore, the seismic resonance coefficient of a structure $(\alpha)$ would be calculated by dividing the fundamental natural period of the structure by the fundamental natural period of the soil deposit (Ghayamghamian and Rahimzade, 2005). With regard to this, if the natural period of the structure is closer to the dominant period of the soil deposit, the vulnerability of the structure would be high and in this situation the resonance coefficient is near 1 . Thus, based on building vulnerability, $\alpha$ classification is as follows: $0.9 \leq \alpha \leq 1.1,1.1<\alpha<1.5$ or $0.5<\alpha<0.9$, and $\alpha \leq 0.5$ or $\alpha \geq 1.5$ (Fig. 4d). 


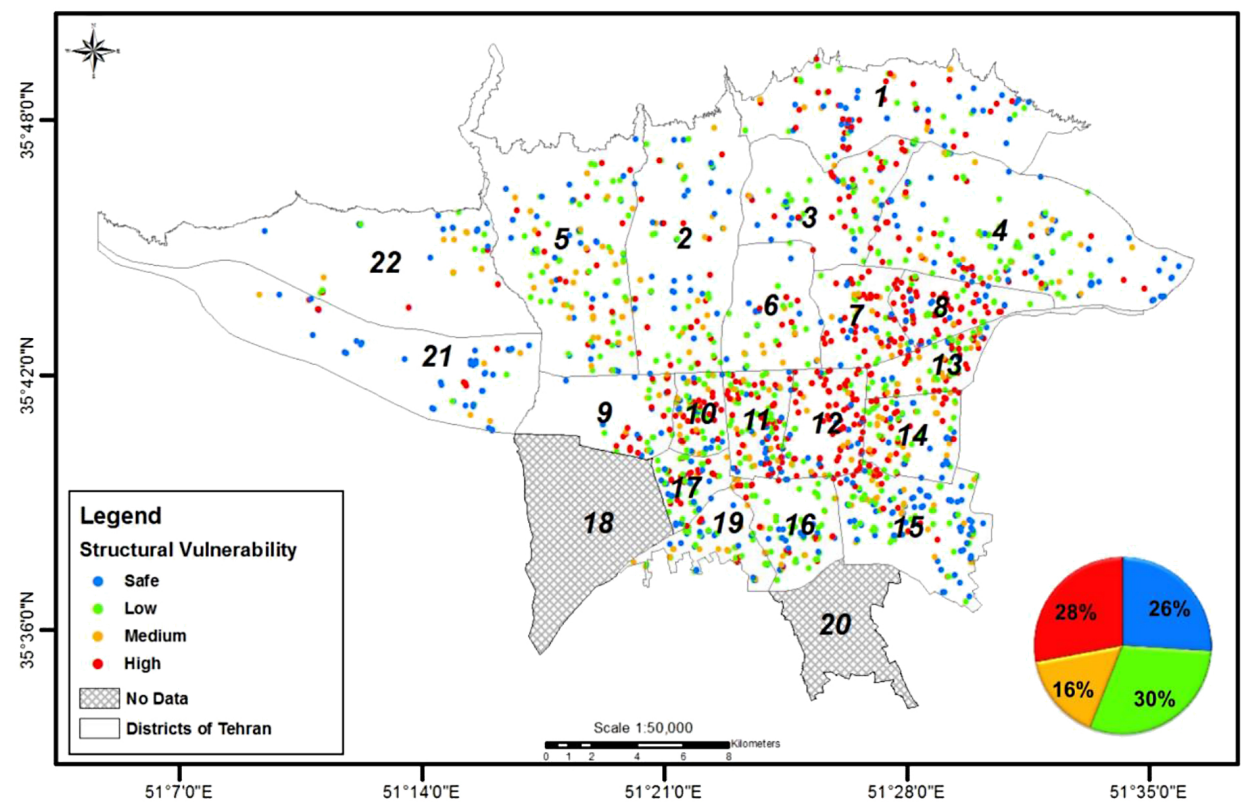

Fig. 5. School distribution showing structural vulnerability in Tehran municipality.

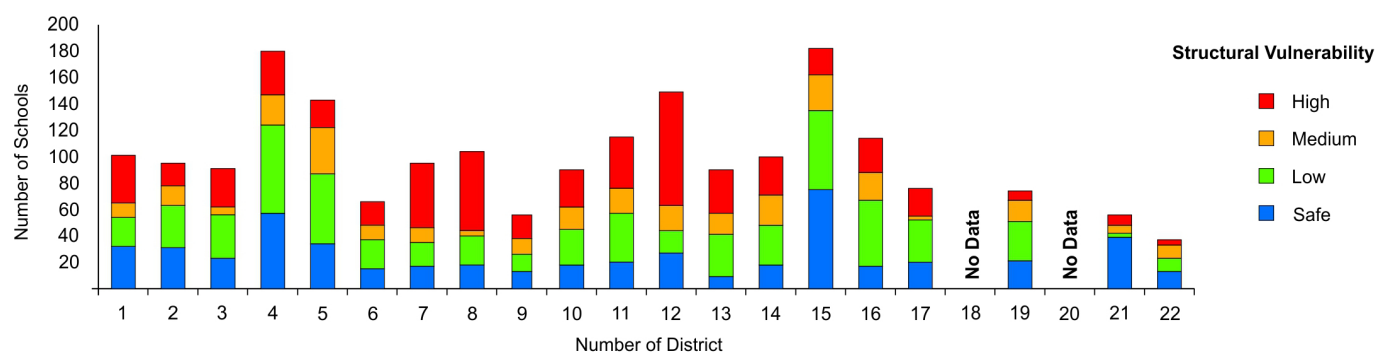

Fig. 6. Number of schools in each district in Tehran municipality and their structural vulnerability.

\section{Results}

After calculating the vulnerability of structures, we classified them into the four categories of high, medium, low and safe, as shown in Figs. 5 and 6. From a statistical viewpoint, $28 \%$ of schools have high, $16 \%$ medium and $30 \%$ low structural vulnerability, and $26 \%$ are classified as safe buildings (Fig. 5). But in terms of geographical distribution, most vulnerable schools are in regions $12,8,7,11,1,4,13$ and 3, while safe schools are located in districts 21 and 22 (Figs. 5 and 6).

Research on the history of these areas indicates the cause of the vulnerability or of the safe condition of existing buildings. Some buildings in districts 11 and 12, which are considered as the central part of Tehran, were constructed during the Qajar era (1924) and most of them have not been renovated because of being cultural heritage. Districts 8,7 and 13 are among the first and oldest settlements of the immigrant citizens and the structures do not conform to the required standards due to a lack of funding, cultural weakness, and a low awareness of their residents, as well as some buildings having been constructed without permission from relevant organizations and authorities. Furthermore, expansion of the city boundaries in districts 1,4 and 3 which contain joined villages, has increased the vulnerability of the structures in these areas. But newly constructed buildings, observance of construction principles as well as municipal government oversight of building construction in districts 21 and 22 have led to safe buildings in these areas.

The final map obtained from processing the geotechnical vulnerability of schools in Tehran is divided into the four categories of high, medium, low and safe, as shown in Figs. 7 and 8. The results showed that $15 \%$ of Tehran's areas have high, $25 \%$ medium and $29 \%$ low vulnerability, and $31 \%$ of the city constitute safe areas (Fig. 7). In terms of geographical location, the central regions of the city towards the north including districts $6,7,8,21,22,1,2,3,4$ and 5 are considered the regions with low or no vulnerability, despite the high slopes in the northern parts, because of the low amplitude of peak ground acceleration and the low 


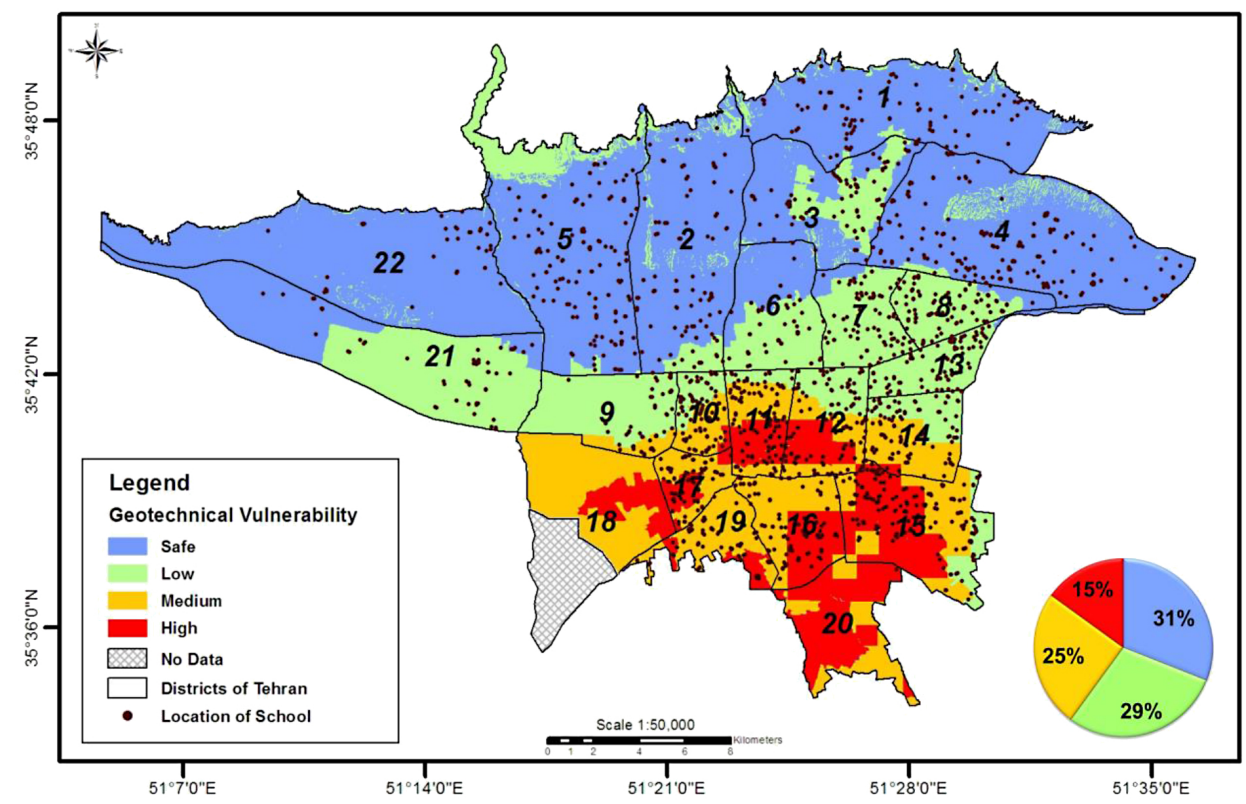

Fig. 7. School distribution showing geotechnical vulnerability in Tehran city.

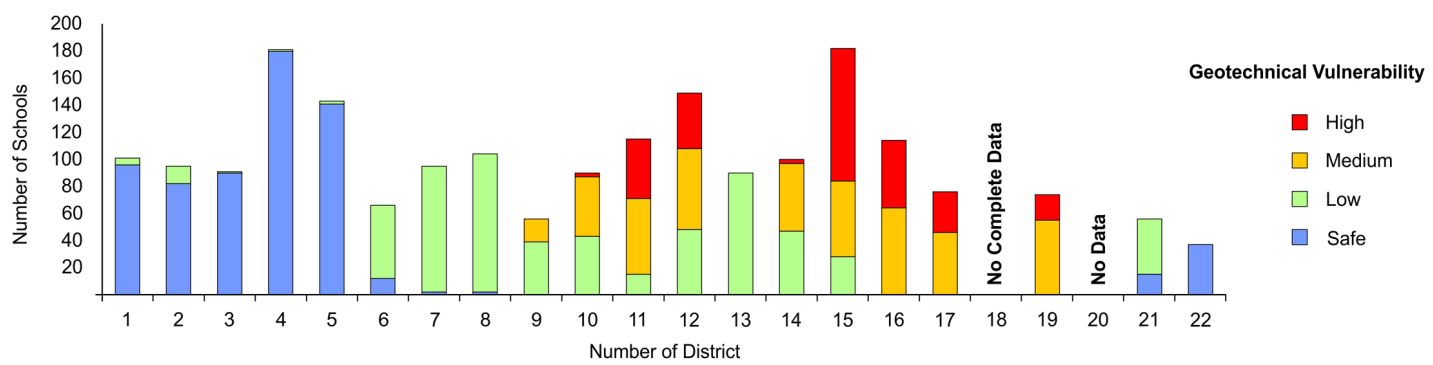

Fig. 8. Number of schools in each district in Tehran city and their geotechnical vulnerability.

probability of liquefaction occurrence. But central to southern regions, especially southeastern areas, namely districts $11,12,15,16,17,18$ and 20, are considered highly vulnerable areas because of the high peak ground acceleration and liquefaction occurrence (Figs. 7 and 8).

Since the main objective of this paper is to determine the seismic vulnerability of the school buildings in Tehran city, the final geotechnical and structural maps have been overlaid, resulting in Fig. 9. The results show that most schools located in districts 12, 15, 11 and 16 as well as some schools in districts 17,18 and 19 have high seismic vulnerability. However, many schools located in districts 4, 5, 1, 2, 3 and 22 and a few schools in districts 6 and 8 would be considered the safest schools in Tehran city.

\section{Discussion}

In this study, the vulnerability of Tehran school buildings has been investigated according to geotechnical and structural criteria and subcriteria by using a combination of GIS and AHP methods. Since all geotechnical and structural criteria, despite having an important role in the vulnerability of schools, do not have the same importance and value, the vulnerability of buildings cannot be reviewed only by inspecting each element individually. Therefore, to achieve the correct results, all elements have been considered simultaneously. Then, geotechnical and structural maps have been overlaid to determine the seismic vulnerability of school buildings (Figs. 9 and 10). Since all schools were divided into four categories (safe, low, medium and high) with regard to structural and geotechnical vulnerability (Figs. 5 and 7), there are 16 scenarios for the assessment of the vulnerability of schools during earthquakes when considering structural and geotechnical conditions together. Meanwhile, to have a better 


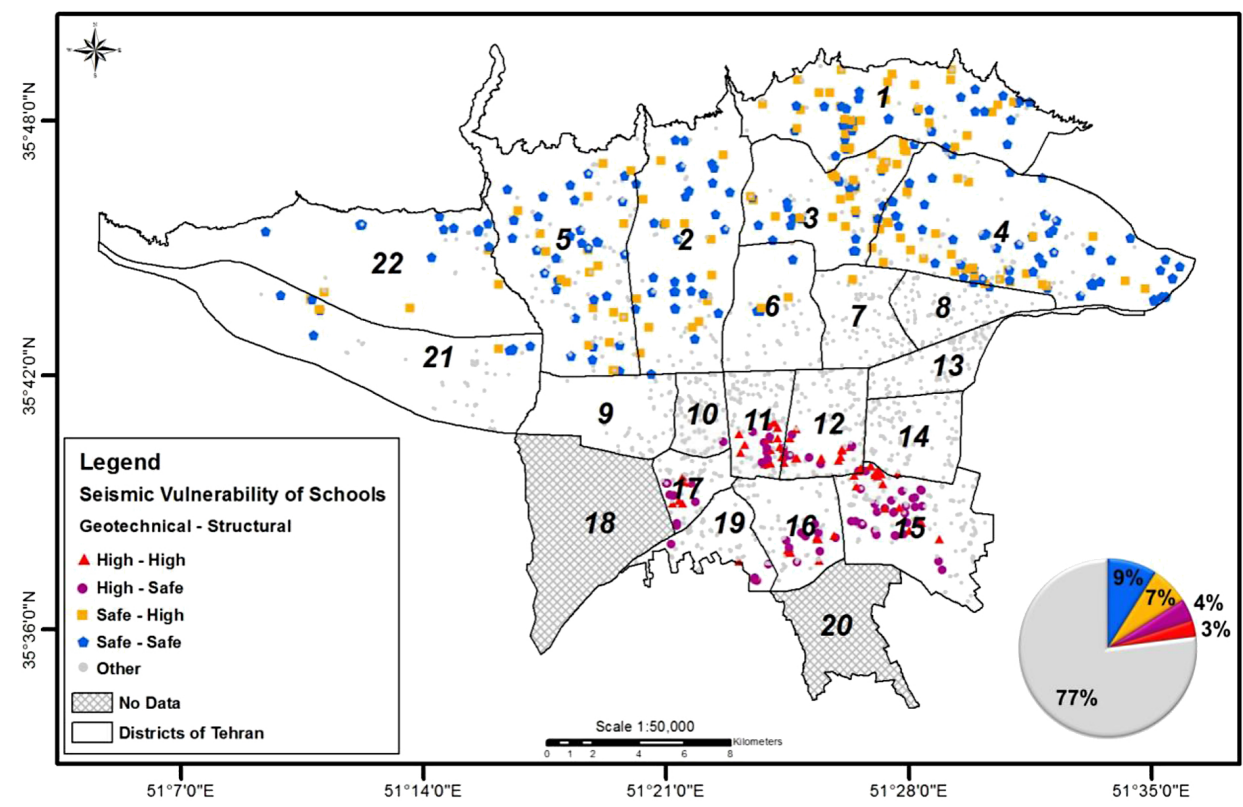

Fig. 9. School distribution showing both geotechnical and structural vulnerability in Tehran city.

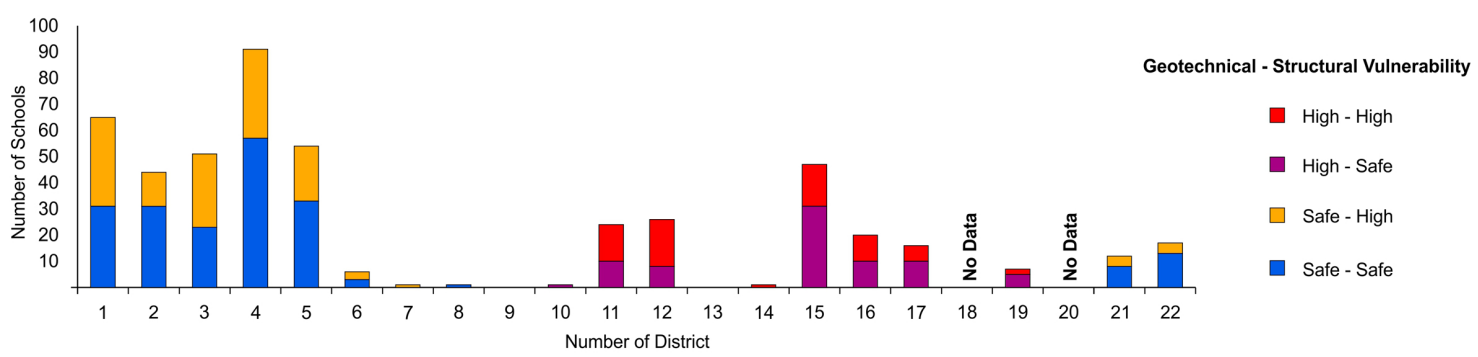

Fig. 10. Number of schools in each district in Tehran city and their geotechnical and structural vulnerability.

understanding of the issue, just four main situations have been explained as follows:

1. schools with high geotechnical and structural vulnerability constitute $3 \%$ of schools, and these are the most vulnerable structures, located in regions 12, 15, 11, 16 and 17 , and should be demolished and reconstructed.

2. schools which have high geotechnical vulnerability and are safe from a structural point of view constitute $4 \%$ of schools in Tehran. These schools are mostly located in districts $15,16,17,11$ and 18, and their seismic vulnerability can be decreased by retrofitting.

3. schools which are safe from a geotechnical point of view and have high structural vulnerability constitute $7 \%$ of schools in Tehran. Most of them are located in districts 1, 4, 3 and 5 and a few in regions 21, 22 and 6. Depending on the age of construction, retrofitting or sometimes demolition and renovation of these schools are the ways to reduce their vulnerability.
4. schools which are safe from both a geotechnical and a structural point of view constitute $9 \%$ of the schools. These schools are located in districts 4, 5, 1, 2 and 3 and a few in regions 22, 21 and 6 and make up one of the safest groups of schools in Tehran.

However, it should be noted that the geographical distribution of the remaining schools not included among the four groups listed above is shown in Fig. 9 and covers $77 \%$ of schools in Tehran. These schools have low or medium vulnerability from the separate viewpoints of structural and geotechnical conditions. Thus, by considering structural and geotechnical conditions together, these schools are much less vulnerable than the schools mentioned above in categories 1 to 3 . Therefore, we can reinforce and make these buildings resistant by using very low-cost and affordable retrofitting techniques against earthquakes. 


\section{Conclusions}

Surveys show that the collapse of buildings and structures during an earthquake can cause huge social, economic and human disasters. Therefore, the construction of earthquakeresistant buildings which can be used as a temporary shelter immediately after the earthquake plays a significant role in saving the lives of the people who reside in the structures that have collapsed. In this context, overlaying geotechnical and structural vulnerability maps is the main step in order to identify vulnerable areas. Therefore, the purpose of the present study is to represent a model for determining the degree of vulnerability of school buildings in Tehran on the basis of spatial analysis and through a combination of AHP and GIS. The important advantages of using these techniques is that they incorporate geotechnical and structural knowledge to develop a seismic vulnerability map. The results showed that in the case of Rey fault movement, 597 schools out of 2125 schools of Tehran city may experience high destruction because of the oldness of their construction. In some cases their reconstruction is impossible because they are part of cultural heritage. The geotechnical vulnerability map also showed that 317 schools can be considered as highly geotechnically vulnerable structures with respect to the occurrence of high peak ground acceleration and soil liquefaction during earthquakes. Finally, regarding geotechnical and structural factors in the seismic vulnerability of school buildings in Tehran city, it can be concluded that only 72 schools have a high geotechnical and structural vulnerability; therefore, they need to be demolished and reconstructed.

Acknowledgements. The authors would like to thank editor and reviewers for valuable suggestions and constructive comments, which improved the quality of the paper. We are also grateful to Mohammad Reza Gheitanchi for his kind help.

Edited by: O. Katz

Reviewed by: two anonymous referees

\section{References}

Aghataher, R., Delavar, M. R., Nami, M. H., and Samnay, N.: A Fuzzy-AHP decision support system for evaluation of cities vulnerability against earthquakes, World Appl. Sci. J., 3, 66-72, 2008.

Amini Hosseini, K., Hosseini, M., Jafari, M. K., and Hosseinioon, S.: Recognition of vulnerable urban fabrics in earthquake zones: a case study of the Tehran metropolitan area, J. Seismol. Earthq. Eng., 10, 175-187, 2009.

Arya, A. S.: Design and construction of masonry buildings in seismic areas, Bulletin ISET, 4, 25-37, 1967.
Ashtari Jafari, M.: Statistical prediction of the next great earthquake around Tehran, Iran, Geodynamics, 49, 14-18, doi:10.1016/j.jog.2009.07.002, 2010.

Askari, F. and Kasaie, M.: Liquefaction evaluation in south eastern of Tehran, Tehran University College of Engineering Journal, Iran, 37, 257-267, 2003 (in Persian).

Berberian, M., Ghorashi, M., Argang Ravesh, B., and Mohajer Ashjaie, A.: Seismotectonics and earthquake-fault hazard investigation in the Tehran Region: contribution to the seismotectonics of Iran, Part V, Report No.56, Geological Survey of Iran, 1985 (in Persian).

BHRC (Building and Housing Research Center): Iranian Code of Practice for Seismic Resistant Design of Buildings, 1st Edn., Iran, 71 pp., 1988 (in Persian).

BHRC (Building and Housing Research Center): Iranian Code of Practice for Seismic Resistant Design of Buildings, 2nd Edn., Iran, 127 pp., 1999 (in Persian).

BHRC (Building and Housing Research Center): Iranian Code of Practice for Seismic Resistant Design of Buildings, publication PNS-253, 3rd Edn., Iran, 135 pp., 2005 (in Persian).

Cole, S. W., Yebang, Xu., and Burton, P. W.: Seismic hazard and risk in Shanghai and estimation of expected building damage, Soil Dyn. Earthq. Eng., 28, 778-794, doi:10.1016/j.soildyn.2007.10.008, 2008.

Dodgson, J. S., Spackman, M., Pearman, A., and Phillips, L. D.: Multi-Criteria Analysis: a Manual, Department for Communities and Local Government, London, available at: http://eprints.lse. ac.uk/12761/ (last access: 2 September 2013), 2009.

Ghayamghamian, M. R. and Khanzade, K.: Buildings classification and determination of damage function for non-engineering in Bam city, J. Seismol. Earthq. Eng., 39, 2-10, 2008.

Ghayamghamian, M. R. and Rahimzadeh, S.: Site effect estimation and classification for BHRC station in Tehran using reference site method, Bulletin IIEES, 8, 14-30, 2005 (in Persian).

Ghayamghamian, M. R., Ahmadzadeh, S., and Mirzaei, N.: Evaluation of damage functions for non-engineering buildings during the 2005 Dahooiyeh-Zarand earthquake in Iran, Civil Engineering Sharif, 27, 13-19, 2012 (in Persian).

Gulati, B.: Earthquake risk assessment of buildings: applicability of HAZUS in Dehradun, India, M.S. thesis, ITC, the Netherlands, 121 pp., 2006.

Hashemi, M. and Alesheikh, A. A.: Development and implementation of a GIS-based tool for spatial modeling of seismic vulnerability of Tehran, Nat. Hazards Earth Syst. Sci., 12, 3659-3670, doi:10.5194/nhess-12-3659-2012, 2012.

Hataminejad, H., Fathi, H., and Eshghabadi, F.: Criterion vulnerability assessment earthquake about city, case study region 10 Tehran, J. Human Geogr. Res., 68, 1-2, 2009 (in Persian).

JICA (Japan International Cooperation Agency) and CEST (Center for Earthquake and Environmental Studies of Tehran, Tehran Municipality): The Study on Seismic Microzoning of the Greater Tehran Area in the Islamic Republic of Iran, Final Report, Iran, 403 pp., 2000.

Mahdizadeh, A.: Report on retrofit procedure of school buildings in Islamic Republic of Iran, Ministry of Education, State Organization of Schools Renovation, Iran, $88 \mathrm{pp}$., available at: http://www.nosazimadares.ir/behsazi/default.aspx (last access: 2 September 2013), 2011. 
Maithani, S. and Sokhi, B. S.: Radius: a methodology for earthquake hazard assessment in urban areas in a GIS environment, Case study Dehradun Municipal area, ITPI, 3, 55-64, available at: http://itpi.org.in/pdfs/july2004/chapter7.pdf (last access: 2 September 2013), 2004.

Malczewski, J.: GIS and Multi-Criteria Decision Analysis, John Wiley, Toronto, 1999.

Malczewski, J.: GIS-based land-use suitability analysis: a critical overview, Prog. Plann., 62, 3-65, 2004.

Nath, S. K. and Thingbaijam, K. K. S.: Seismic hazard assessment a holistic microzonation approach, Nat. Hazards Earth Syst. Sci., 9, 1445-1459, doi:10.5194/nhess-9-1445-2009, 2009.

Rashed, T. and Weeks, J.: Assessing vulnerability to earthquake hazards through spatial multi criteria analysis of urban areas, Int. J. Geogr. Inf. Sci., 17, 547-576, 2003.

Saaty, T. L.: A scaling method for priorities in hierarchical structures, J. Math. Psychol., 15, 234-281, doi:10.1016/00222496(77)90033-5, 1977.

Saaty, T. L.: The Analytic Hierarchy Process, McGraw-Hill, New York, 1980.

Saaty, T. L.: Rank from comparisons and from ratings in the analytic hierarchy/network processes, Eur. J. Oper. Res., 168, 557-570, doi:10.1016/j.ejor.2004.04.032, 2004.

Safari, A. and Moghimi, A.: Geomorphologic assessment of urban development and vulnerability caused by landslide in mountainous hillsides of Tehran metropolis, J. Phys. Geogr. Res., 41, 5371, 2010 (in Persian).

Seed, H. B. and Idriss, I. M.: Simplified procedure for evaluating soil liquefaction potential, J. Soil Mech. Foundations Division, 97, 1249-1273, 1971.
Servi, M.: Assessment of vulnerability to earthquake hazards using spatial multi criteria analysis: Odunpazari, Eskisehir case study, M.S. thesis, Middle East Technical University, Turkey, 94 pp., 2004.

Sharifzadegan, M. H. and Fathi, H.: Application of seismic risk assessment models in urban planning and design, Soffeh (Journal of Architecture and Urban Planning Faculty of Shahid Beheshti University), 46, 109-124, available at: http://www. sid.ir/en/ViewPaperprint.asp?ID=211079\&varStr= (last access: 2 September 2013), 2008 (in Persian).

Tavakoli, B. and Tavakoli, S.: Estimating the vulnerability and loss functions of residential buildings, Nat. Hazards, 7, 155-171, doi:10.1007/BF00680428, 1993.

Thapaliya, R.: Assessing building vulnerability for earthquake using field survey and development control data: a case study in Lalitpur sub metropolitan city, Nepal, Ms. thesis, ITC, the Netherlands, 103 pp., 2006.

Zahraie, M. and Ershad, L.: Study on seismic vulnerability of building structures in Qazvin, Journal of Faculty of Engineering (University of Tehran), 39, 287-297, 2005 (in Persian).

Zangiabadi, A. and Tabrizi, N.: Tehran earthquake and spatial analysis on urban area vulnerability, J. Geograph. Res., 38, 115-130, 2000 (in Persian).

Zekai, S.: Supervised fuzzy logic modelling for building earthquake hazard assessment, Expert Syst. Appl., 38, 14564-14573, doi:10.1016/j.eswa.2011.05.026, 2011. 